\title{
PROPOSTA DE INOVAÇÃO PARA O PRODUTO MICTÓRIO: APLICAÇÃO DO PDP EM PROJETO EXECUTADO POR ÚNICO PROJETISTA
}

Anderson Gomes Ferreira (anderson.goferreira@gmail.com) - Universidade Federal de Minas Gerais

Luciano Murta (luciano.murta@gmail.com) - Universidade Federal de Minas Gerais

Bárbara Rangel de C. Braga de Mendonça (barbarademendonca@gmail.com) - Universidade Estadual de Minas Gerais

Rudolf Huebner (rudolf@ demec.ufmg.br) - Universidade Federal de Minas Gerais

Eduardo Romeiro (romeiro@ dep.ufmg.br) - Universidade Federal de Minas Gerais

\section{RESUMO}

O produto mictório masculino é tido como excelente solução para a coleta da urina, sendo apontado como produto de alta sustentabilidade devido ao baixo consumo de água. Contudo, o mesmo apresenta baixa eficiência de coleta, sendo comum a "justificativa" que tal problema se origina pela utilização inadequada. A pesquisa partiu do princípio que o processo de desenvolvimento de produtos $(P D P)$ deve ser orientado para desenvolver produtos que se adaptem aos usuários, e não o inverso. Desse modo, a concepção de produto deve ser orientada a produzir o mínimo de prescrições. Por meio da aplicação do PDP, de ferramentas de criatividade e simulações virtuais, desenvolveu-se um projeto inovador de mictório que busca manter o baixo consumo de água e permitir eficácia na coleta. Obteve-se como resultado um design inovador e uma análise da aplicação do PDP e técnicas de inovação em projetos conduzidos por um único projetista, seguindo estratégias do Lean Product Development. Comparou-se o desenvolvimento de projetos inovadores por apenas um projetista com conhecimento multidisciplinar em relação a projetos que exigem a integração de vários projetistas em um time multidisciplinar. Concluiu-se que, mesmo para o desenvolvimento de produtos com apenas um projetista, aplicar um PDP estruturado é altamente vantajoso.

Palavras chave: PDP equipe pequena; inovação único projetista, projeto de produto inovador, inovação e PDP

Área: Lean Product Development

\section{INTRODUÇÃO}

O mictório masculino destaca-se como produto que permite a economia de água, por ter menos consumo do recurso que o vaso sanitário padrão. Contudo, o projeto atual mais utilizado nos banheiros, apresentado na Figura 1, é um produto que apresenta diversos problemas em sua funcionalidade, como a baixa eficácia da coleta da urina, excesso de respingos e não atender a crianças. 
Figura 1. Dimensões do Mictório acessível suspenso. Fonte: NBR 9050 (2015).

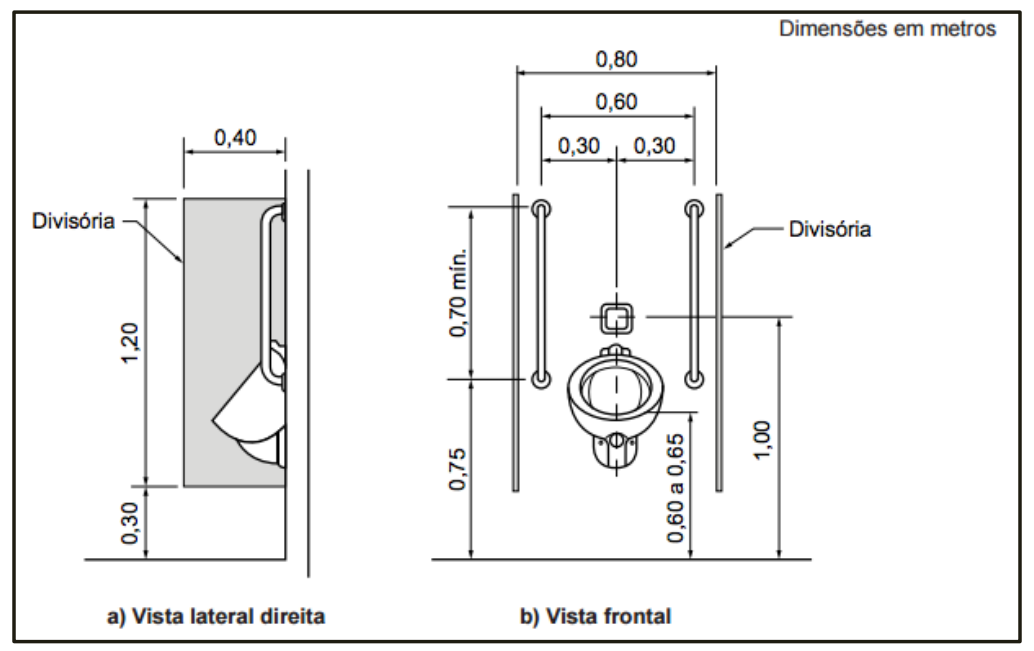

A partir da hipótese de que é possível o desenvolvimento de um novo produto que permita alta eficiência por meio do trabalho de único designer, a pesquisa teve como objetivo o desenvolvimento de um projeto conceitual de mictório que permita a solução dos problemas levantados mantendo a grande qualidade do projeto atual de apresentar baixo consumo de água. Analisou-se durante o processo a aplicação de um PDP estruturado por parte de um único profissional projetista.

\section{REFERENCIAL TEÓRICO}

A compreensão de três conceitos torna-se importante para compreensão dos resultados da pesquisa: Processo de desenvolvimento de produto, Vazão e velocidade do jato de urina masculino e o efeito Coanda.

\subsection{Processo de desenvolvimento de produto}

O desenvolvimento de novos produtos a partir de uma ideia inicial é um processo gradual de redução da incerteza com base em uma série de estágios de solução de problemas, avaliação, seleção e implementação que conectam o fluxo de mercado e tecnologia. Entre os vários fatores que influenciam o sucesso de um produto está a percepção do cliente da vantagem do produto, conhecimento do mercado e definição clara do produto. Alguns métodos convencionais de pesquisa de mercado são insuficientes e, às vezes, enganosos. Em tais casos é melhor observar o uso de protótipos, identificando-se necessidades latentes ou exigências não explicitadas verbalmente (TIDD; BESSANT; PAVITT, 2015).

O Processo de Desenvolvimento de Produto refere-se ao conjunto de atividades interdisciplinares que se iniciam na percepção de uma oportunidade de mercado e é concluído com a implantação de um sistema de produção e vendas do produto, o que passa por fases de planejamento, concepção, prototipagem, etc. (ULRICH; EPPINGER, 2011).

O desenvolvimento de um conceito de produto não acontece espontaneamente por um golpe de criatividade, em vez disso, o bom resultado vem por meio de uma estruturação de passos que pretende articular a abordagem do problema, incluindo técnicas a serem utilizadas em cada fase (DYM; LITTLE; ORWIN, 2013, p. 15).

A criatividade em geral resulta de um trabalho mental para a realização de associações, combinações, conclusões a partir de ideias existentes (BAXTER, 1998, p. 93). 
A habilidade de inovar vai além do processo criativo. Um grande número de boas ideias nunca chegam ao mercado na forma de um produto ou serviço capaz de gerar valor financeiro e gerar lucro. A abordagem Lean Product Development tem como objetivo de obter ideias e transformar as mesmas em produtos que geram valor com a maior velocidade possível, com a eliminação de processos e atividades não essenciais ao processo, maximizando o valor e minimizando atividade. (RADEKA, 2012, p. 3).

O processo criativo individual é aquele baseado apenas no pensamento e conhecimento de uma única pessoa, o que certamente será influenciado pela sua personalidade, ambiente e motivação pessoal. A habilidade cognitiva mais importante para o processo criativo individual é a de analisar os problemas de um modo não tradicional, propondo ideias e selecionando as que valem a pena serem melhor trabalhadas. $\mathrm{O}$ conhecimento sobre o campo da inovação por parte do indivíduo criativo deve ser de alto nível, a ponto de permitir que as suas soluções sejam factíveis, mas não deve ser especialista, de modo a não permitir o pensamento diferente dos estudos já realizados e impedir a integração com outras áreas (SCHILLING, 2013, p. 20).

A personalidade que permite uma melhor criatividade é aquela que possui o seis específicos caracteres de personalidade: auto-eficácia, tolerância para ambiguidade, disposição para superar obstáculos, disposição para assumir riscos de modo racional e motivação intrínseca (SCHILLING, 2013, p. 20).

A gama de inovações observadas na atividade econômica é classificada em inovação radical ou inovação incremental (FREEMAN; SOETE, 1997). As inovações incrementais abrangem melhorias feitas no design ou na qualidade dos produtos, aperfeiçoamentos em layout e processos, novos arranjos logísticos e organizacionais e novas práticas de suprimentos e vendas. Tais inovações não se originam necessariamente de processos de $\mathrm{P} \& \mathrm{D}$.

As múltiplas incertezas que cercam a atividade econômica levam as empresas a buscarem estratégias competitivas específicas de acordo aos mercados em que atuam e com os seus objetivos (TIGRE, 2014, p. 181).

A estratégia empresarial pode ser definida como a seleção explícita de um conjunto de objetivos alinhados com a finalidade de adaptar a empresa ao ambiente externo ou modificar esse ambiente para melhorar suas chances de sucesso, conforme seja a interpretação do que é sucesso para essa empresa (COOMBS; SAVIOTTI; WALSH, 1992).

Assim, embora o processo criativo possa ser realizado por uma única pessoa, a condução da atividade de inovação deve ser compartilhada com a gestão da empresa, de modo a garantir o alinhamento estratégico. Desse modo, a pesquisa conduzida também foi orientada a atender objetivos específicos de posicionamento estratégico de mercado para realização de patenteamento e comercialização da invenção.

\subsection{Vazão e velocidade do jato de urina masculino}

O volume médio de líquido descartado durante o processo de urinar é de $195 \mathrm{ml}$ para homens e de $171 \mathrm{ml}$ para mulheres e a vazão média é de $11 \mathrm{ml} / \mathrm{s}$ para homens e de $15 \mathrm{ml} / \mathrm{s}$ para mulheres (RICHIE, 1990).

A vazão é controlada pela contração e relaxamento dos músculos da bexiga e este processo é controlado por vários nervos e sistemas hormonais causando uma grande variação na velocidade ao longo do tempo (ANDERSSON; ARNER, 2004)

Para efeito da simulação do fluxo urinário no desenvolvimento do protótipo virtual, foram os usados os parâmetros de velocidade conforme mostrado na Figura 2. 
Figura 2: Variação da velocidade do fluxo urinário com o tempo. Fonte: Elaborado pelo autor.

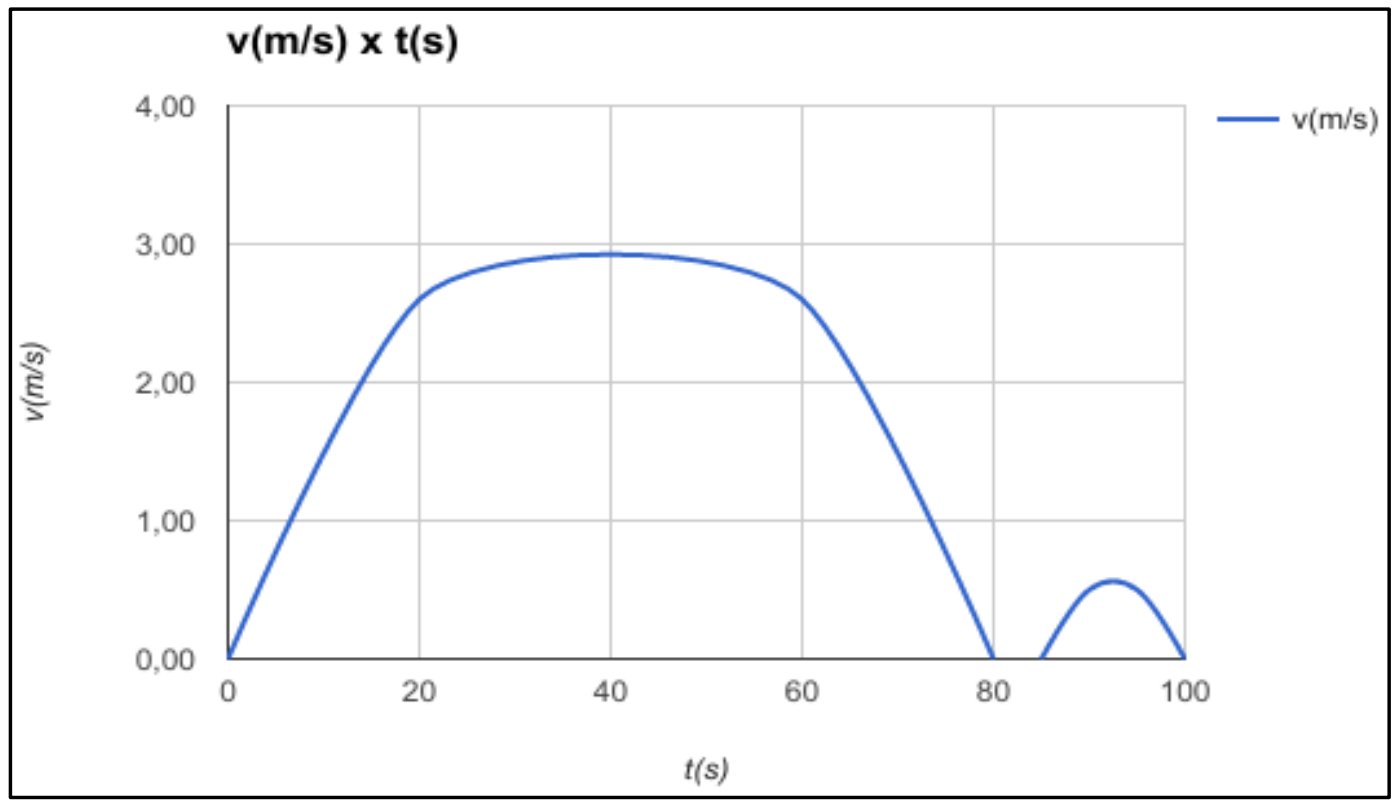

\subsection{Efeito Coanda}

O efeito Coanda é encontrado em vários aplicações de aerodinâmica e pode ser descrito como a tendência de um fluido se prender à uma superfície curva que esteja orientada perpendicular à direção do fluxo (DRAGAN, 2012). Tal efeito é esquematizado na Figura 3.

Figura 3: A configuração geométrica de um jato de parede curva - demonstração do efeito Coanda. Fonte: Adaptado de Dragan (2012).

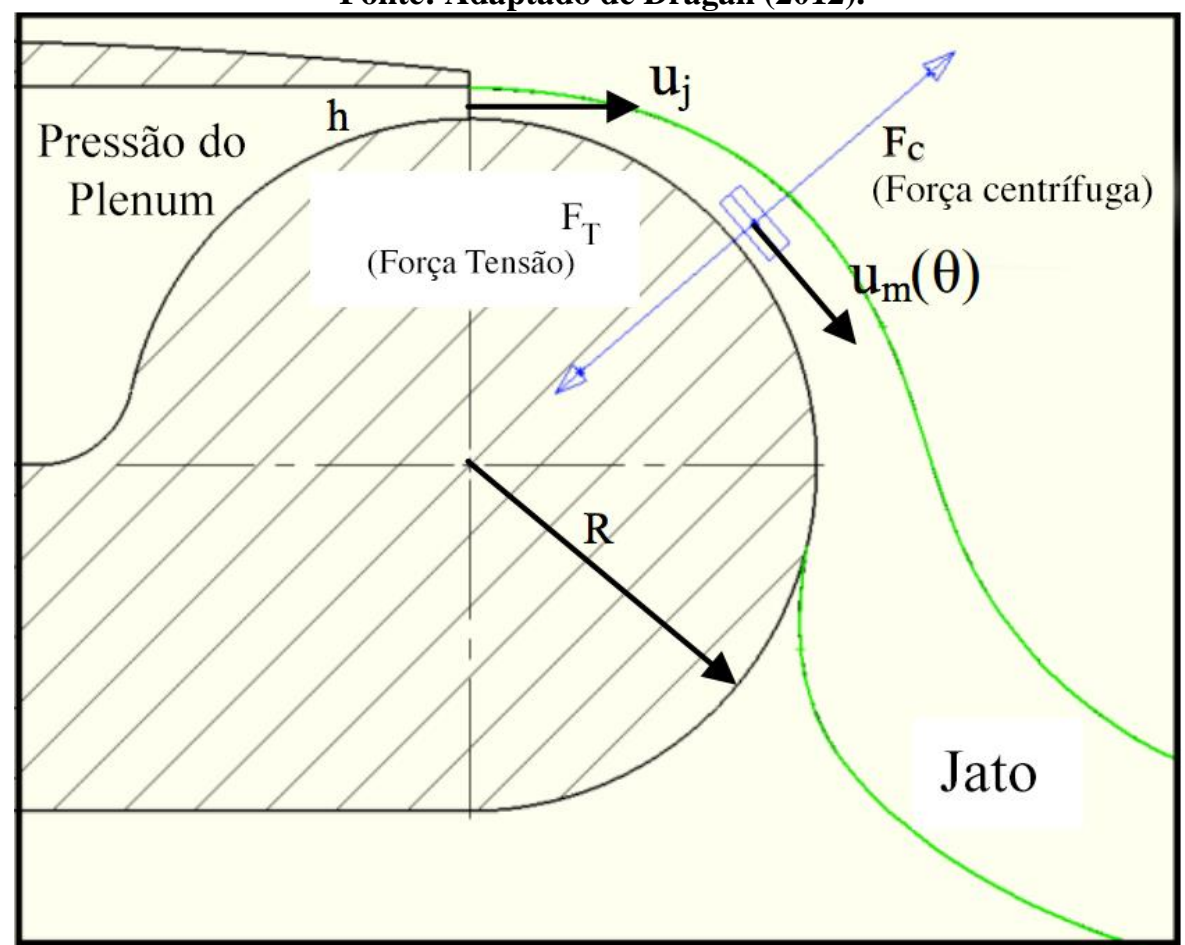

A melhor forma para evitar que não ocorram respingos ao urinar (splash-backs) é evitar direcionar o fluxo urinário diretamente para as paredes do mictório. É preciso fazer com que o fluxo atinja a superfície o mais paralelo à superfície possível (PHAM; YANG; CHOO; HU, 2013). Essa estratégia é apresentada na Figura 4. 
Figura 4: Aparato desenvolvido para simular a urina masculina. Fonte: Truscott e Hurd (2017).

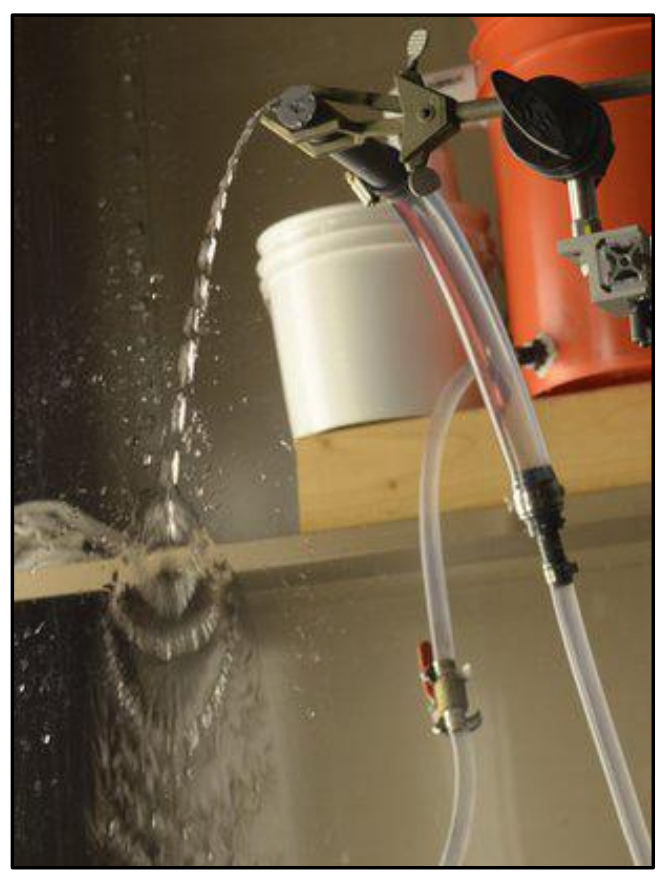

\section{METODOLOGIA}

A pesquisa avaliou o processo de inovação oriunda de um único designer, prática que se mostra importante dada a meta de redução máxima de recursos objetivada pelo Lean Product Development (RADEKA, 2012).

A metodologia adotada para o desenvolvimento da pesquisa consistiu de observação sistemática do projetista incumbido de realizar o novo projeto conceitual, e de entrevistas estruturadas realizadas ao longo do processo. $\mathrm{O}$ trabalho do projetista foi guiado em um PDP consistente de cinco fases sequenciais que são apresentadas na Figura 5.

Figura 5: Fluxograma da metodologia de trabalho adotado pelo projetista. Fonte: Elaborado pelo autor.

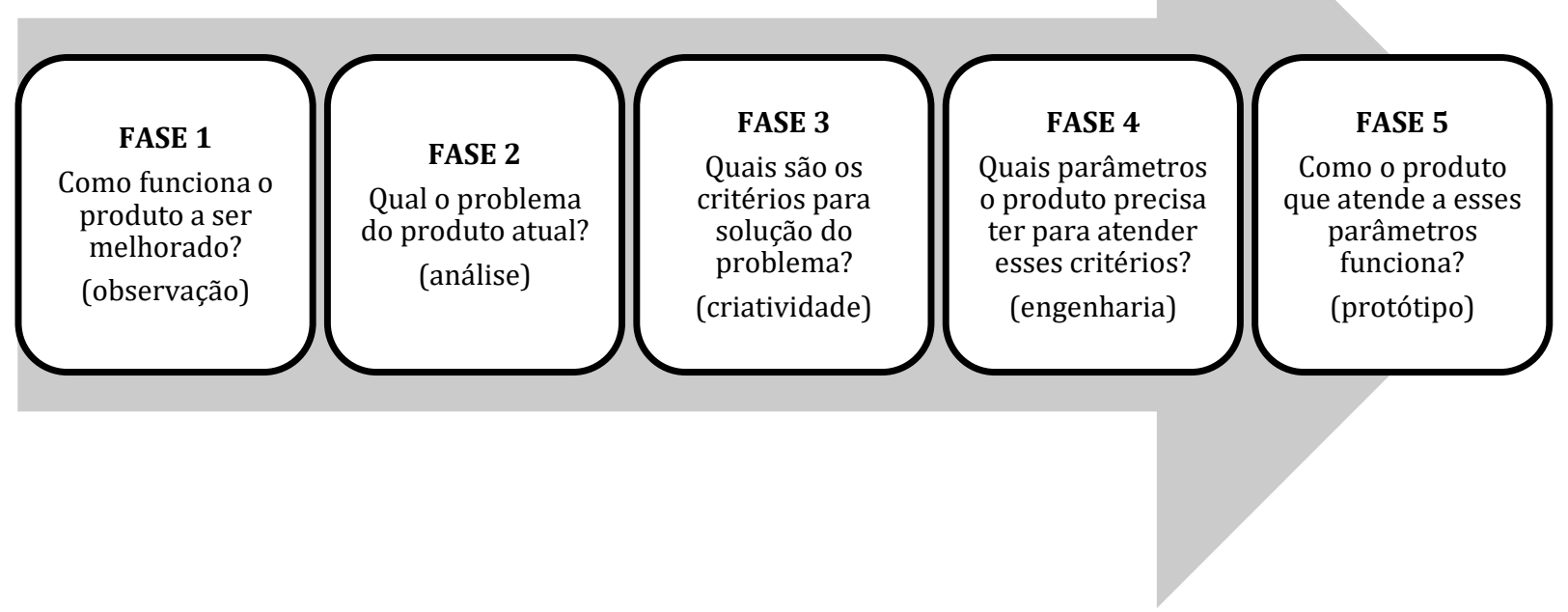




\subsection{Como o produto a ser melhorado funciona?}

Nessa fase realizou-se a simulação do fluxo de urina masculino e a representação de como o produto atual funciona.

Observou-se que ao final do processo, o fluxo é brevemente interrompido e volta com uma velocidade bem menor por um curto período de tempo. A Figura 6 apresenta os principais frames da simulação do funcionamento do projeto atual de mictório.

Figura 6: Simulação do funcionamento do projeto atual de mictório. Fonte: Elaborado pelo autor.

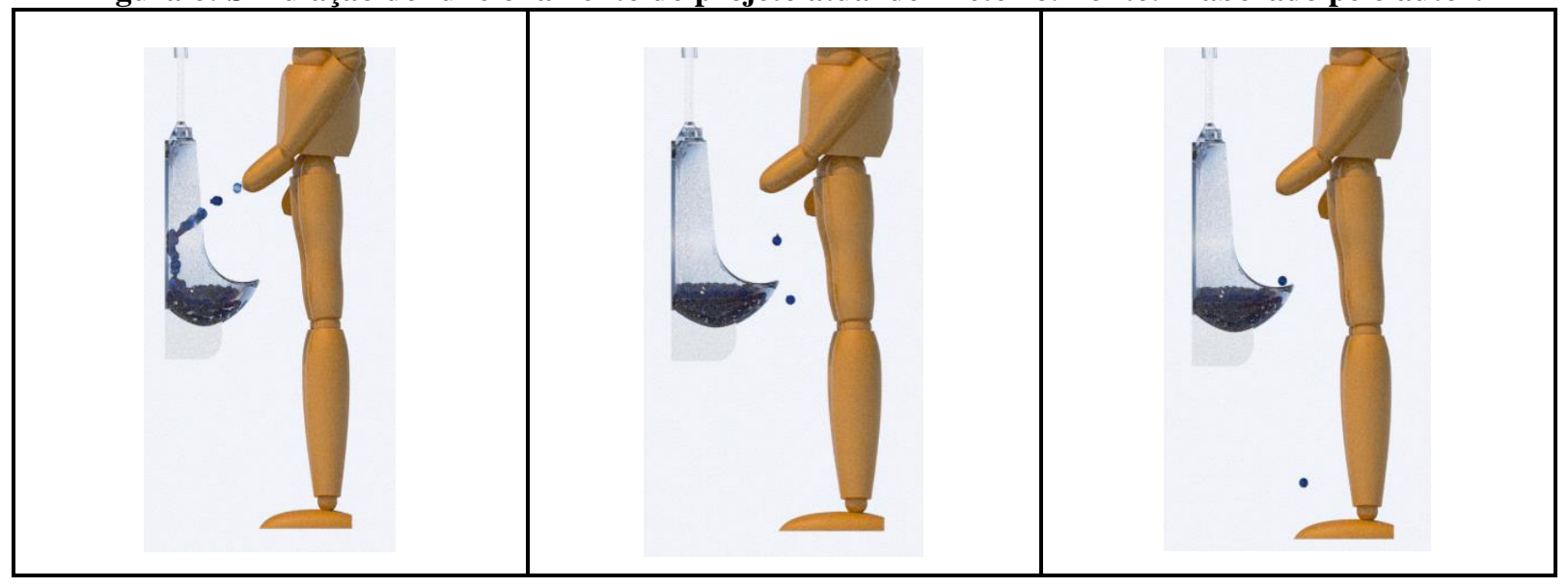

\subsection{Qual o problema do produto atual?}

Analisando as simulações, observou-se que devido a redução da velocidade nos últimos segundos ocasiona alteração na direção do volume final do jato, permitindo uma queda do mesmo em direção próxima da vertical, o que é a causa raiz da ineficiência de coleta do projeto de mictório tradicional, que não considera esse jato final. Outros problemas são a dimensão que permite uma estreita faixa de altura, que impede utilização por crianças, e o excesso de respingos gerado quando o jato é direcionado a um choque em $90^{\circ} \mathrm{com}$ a parede de coleta. Enumerando tais problemas, temos:

1. Baixa eficácia na coleta da urina;

2. Gera respingos sobre o usuário;

3. Não atende crianças.

\subsection{Quais são os critérios para solução do problema?}

Durante a fase de determinação dos critérios de projeto (definition phase), fase que deve perceber a proposta do projeto conceitual, tem-se como objetivo o entendimento do problema a que o produto deve resolver (ULLMAN, 2010, p. 87).

Realizou-se a determinação dos critérios para coleta da urina completa partindo-se do princípio que entendendo o problema pode-se determinar quais os critérios o produto deve apresentar de modo a resolver o mesmo. Por meio da análise do fluxo de urina, identificou-se que a solução para a plena eficiência de coleta da urina deve atender aos quatro seguintes critérios:

1. Coletar urina que cai sob um ângulo próximo de $0^{\circ}$;

2. Não gerar respingo após atingimento da urina ao local de coleta;

3. Permitir faixa de coleta em um faixa horizontal de $300 \mathrm{~mm}$;

4. Atender faixa de antropometria da criança ao homem adulto. 


\subsection{Como o produto que atende a esses parâmetros funciona?}

Com o objetivo de promover a inovação incremental que solucione os problemas levantados, analisou-se quais devem ser os parâmetros do produto para que os critérios anteriormente levantados sejam satisfeitos.

Nesse momento foi desenvolvido estudo de engenharia para compreender os fenômenos físicos envolvidos no processo de coleta de líquidos. São eles os fenômenos de Coanda e splash-back, apresentados resumidamente no referencial teórico da presente pesquisa. A união destes dois conceitos deu origem aos critérios de projeto para o novo mictório: uma forma com secção para maximizar o efeito Coanda e minimizar o efeito splash-back. Por meio desse estudo identificou-se que o conceito de produto deve possuir os seguintes parâmetros:

1. Superfície prolongada para permitir coleta sob um ângulo de $0^{\circ}$, tendo aparo de coleta debaixo do usuário.

2. Curva gradual sobre a superfície de coleta para evitar o fluxo atinja a superfície com um ângulo de $90^{\circ}$ e gere respingos.

3. Formatação da superfície para favorecer o aparecimento do efeito Coanda.

4. Área lateral que permitir faixa de coleta em uma faixa horizontal de mínimo $300 \mathrm{~mm}$.

5. Inclinação e altura que permitam a utilização por crianças (altura mínima de um metro) e por adultos (altura máxima de 2 metros e $10 \mathrm{~cm}$ ).

Estabelecer sugestões para tais problemas "originais" auxilia o desenvolvimento do projeto conceitual do produto por atender aos parâmetros de projeto, que respondam aos critérios estabelecidos. Para geração de ideias conceito que atendam aos parâmetros determinados foram utilizadas as seguintes ferramentas de criatividade individual: brainstormings com síntese criativa e pensamento estruturado e vertical. A partir disso obtiveram-se um conjunto de ideias. Demonstrou-se a não dependência de um time de projetistas para a adequada geração de ideias. O projeto conceitual desenvolvido a partir de tais parâmetros é apresentado na Figura 7 por meio de modelamento computacional.

Figura 7: Modelamento do projeto conceitual (à esquerda) e perfil geométrico do projeto conceitual do novo mictório proposto (à direita). Fonte: Elaborado pelo autor.

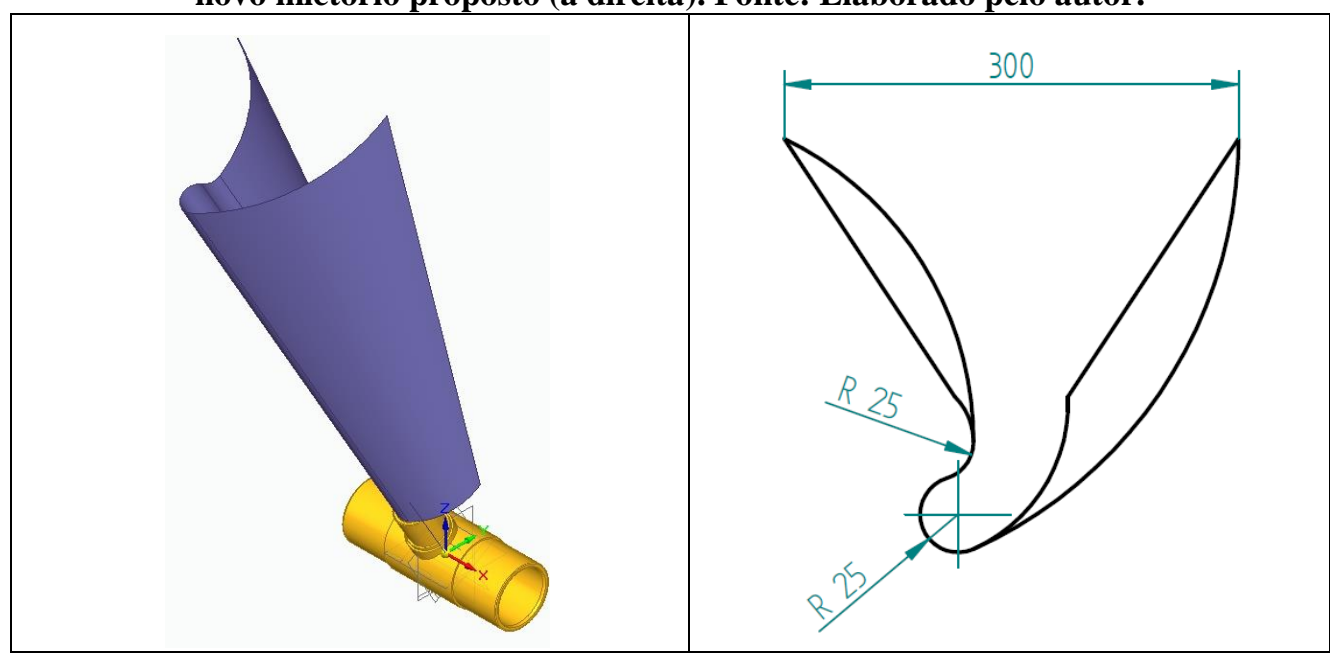

\subsection{Como o produto que atende a esses parâmetros funciona?}

Para avaliar a eficácia do projeto conceitual obtido foram realizadas simulações de funcionamento por meio de protótipos virtuais que demonstram como o mesmo funciona, conforme a Figura 8. 
Figura 8: Simulação de funcionamento do mictório proposto. Fonte: Elaborado pelo autor.

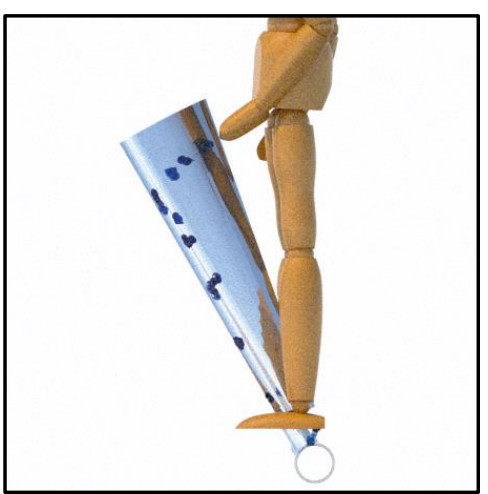

Por meio de modelagem virtual do produto em contexto de uso por meio da aplicação da ferramenta Realflow, compreendeu-se o funcionamento do projeto proposto em um vídeo de 30 segundos cujo os frames principais apresentados na Figura 9 demonstram o resultado, tomando por diferentes vistas.

Figura 9: Frames da simulação do de uso mictório em diferentes vistas. Fonte: Elaborado pelo autor.

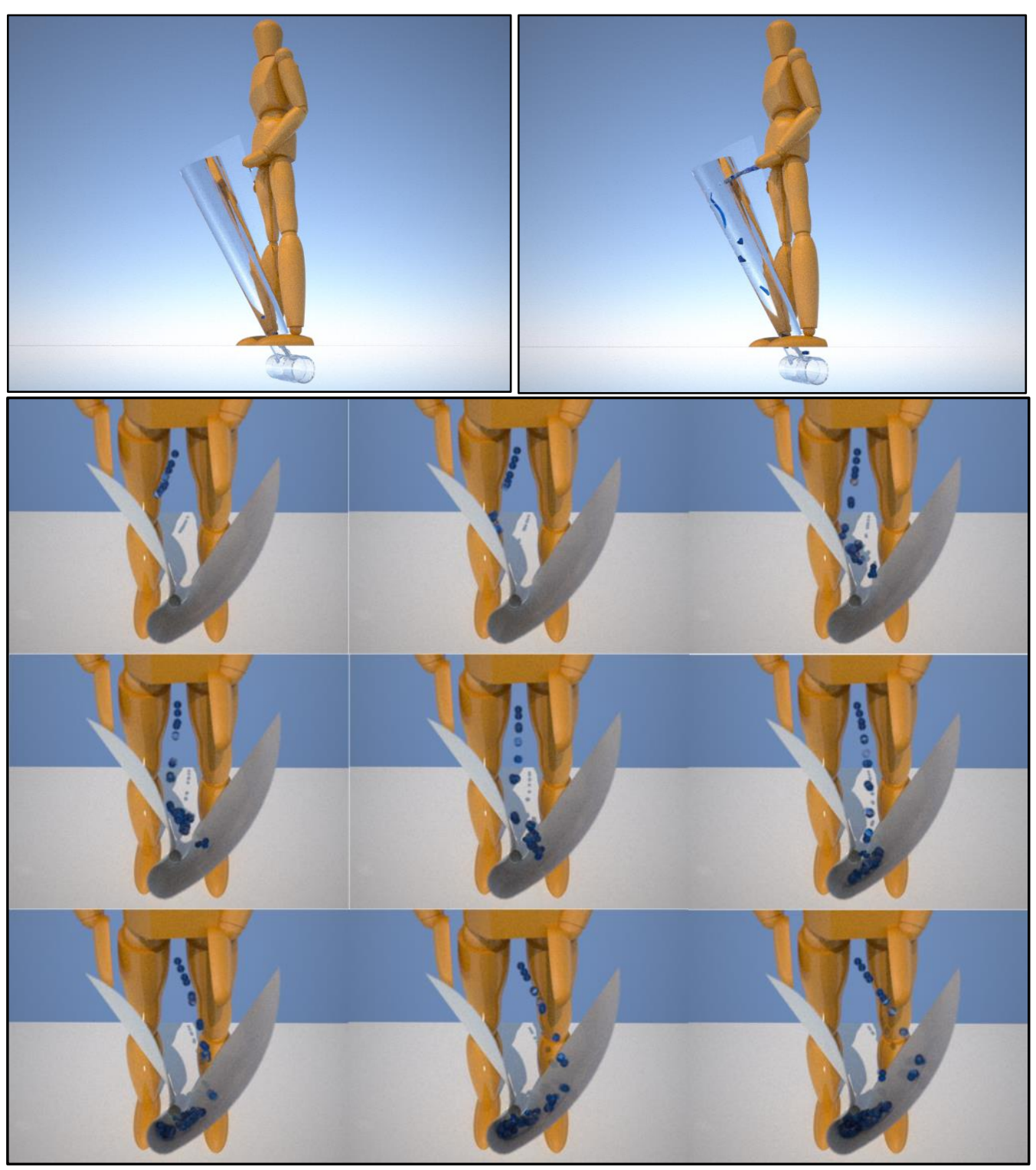


O novo produto foi orientado a possuir processo de manufatura simplificado, consistido de único material (chapa metálica), com processo de fabricação realizado por conformação a frio e união por solda. Uma avaliação comparativa do novo produto em relação ao produto tradicional foi desenvolvida para demonstrar a aplicabilidade do novo conceito, ambos produtos são representados na Figura 10.

Figura 10: Comparação da instalação do mictório tradicional ao projeto conceitual do mictório proposto. Fonte: Elaborado pelo autor.

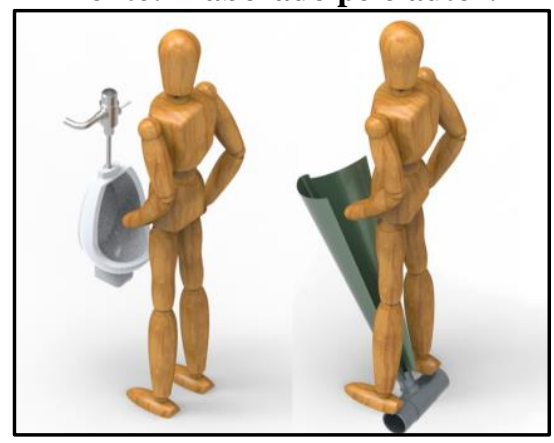

\section{RESULTADOS E DISCUSSÃO}

Evidenciou-se que o atual projeto de mictório não possui alta eficiência de coleta de urina em função do não atendimento aos critérios de projeto descobertos na fase 3 da pesquisa. Demonstrou-se verdadeira a hipótese de que é possível desenvolver um produto que permita alta eficiência na coleta da urina, sendo para isso proposto um projeto conceitual inovador para solucionar o problema, tendo sido tal projeto executado por um único projetista. A adoção de único projetista tem como vantagens não dispêndio de tempo em reuniões e não ocorrência de erros devido falhas na comunicação entre integrantes de um mesmo time. Destacou-se a efetividade e simplicidade do PDP de 5 fases adotado pelo projetista. Mesmo para o desenvolvimento de produtos com apenas um projetista, aplicar um processo de desenvolvimento de produtos estruturado é altamente vantajoso, permitindo o rápido desenvolvimento de inovações incrementais.

A efetividade do pensamento individual enquanto técnica de aprendizado e modelo de criatividade para desenvolvimento de novos produtos provou ser uma habilidade valiosa na geração de inovação incremental em produtos. A ausência de interatividade caracterizada pela integração de diferentes participantes de forma a permitir que as competências de uns possam ser melhoradas e desenvolvidas por outros, unindo diferentes ideias e reformulando novos caminhos cognitivos que a princípio eram inviáveis, não foi problema ao longo do processo. Em entrevista estruturada junto ao projetista, o mesmo confirmou a importância dos seis caracteres de personalidade referenciados pela literatura técnica como fundamentais para o processo criativo individual. Conclui-se que é possível e eficaz estimular a frequência do comportamento criativo (geração de ideias) por meio da aplicação da técnica do pensamento estruturado. O desempenho criativo do desenvolvimento de ideias não deve ser destinado apenas aos casos de geração espontânea que ocorre com devaneios esporádicos não deliberados, onde um insight isolado é obtido pelo pensamento fortuito e espontâneo.

\section{AGRADECIMENTOS}

Agradecimentos ao professor Eduardo Romeiro pelo apoio do LIDEP (Laboratório Integrado de Design e Engenharia do Produto). Agradecimento ao professor Rudolf Huebner pelo apoio 
do LabBio (Laboratório de Bioengenharia). Agradecimentos à FAPEMIG pelo apoio financeiro ao desenvolvimento da pesquisa.

\section{REFERÊNCIAS}

ANDERSSON, K.E., \& ARNER, A. Urinary bladder contraction and relaxation: physiology and pathophysiology. Physiological Reviews, v84, n.3, p.935-986, July, 2004. Maryland, USA. Disponível em: <https://doi.org/10.1152/physrev.00038.2003>.

ASSOCIAÇÃO BRASILEIRA DE NORMAS TÉCNICAS, Acessibilidade a edifcações, mobiliário, espaços e equipamentos urbanos, $3^{\text {a }}$ edição, NBR 9050, ABNT, Rio de Janeiro, 11/10/2015. 48 p.

BAXTER, M. Product Design - A practical guide to systematic methods of new product development. 1st ed. Brunel, United Kingdom: Chapman \& Hall, 2002. 308 p.

COOMBS R., SAVIOTTI P., WALSH V. Technological Change and Company Strategies: Economic and Sociological perspectives.London: Harcourt Brace Jovanovich, 1992.72-102 p.

DYM, C. L.; LITTLE, P.; ORWIN, E. Engineering Design: A Project Based Introduction. 4th ed. Hoboken: Wiley, 2013.

FREEMAN C., SOETE L. The Economics of Industrial Innovation. 3rd edition. Cambridge, MA: MIT Press 1997. 480 p.

RADEKA, K. The Mastery of Innovation: A Field Guide to Lean Product Development. Danvers: CRC Press Taylor and Francis Group, 2012. 265 p.

RICHIE, J. P.. Maximum and average urine flow rates in normal male and female populations

- The Liverpool nomograms: Editorial comment. Journal of Urology, v143, n.6, p.30-38, Liverpool: England, 1990.

SCHILLING, M. A. Strategic Management of Technological Innovation. 4th ed. v.53 New York: McGraw-Hill, 2013.

TIDD, J.; BESSANT, J.; PAVITT, K. Gestão da Inovação. 5a ed. Porto Alegre: Bookman, 2015. $633 \mathrm{p}$.

TIGRE, P. B. Gestão da Inovação - A economia da tecnologia no Brasil. 2a ed. São Paulo: Elsevier, 2014. 296 p.

TRUSCOTT, T.; HURD, R. Splashlab - Utah State University's Premiere Incompressible Fluids Lab. (n.d.). Logan, Utah, 2013. Disponível em: < https://splashlab.org/>.

ULlMAN, D. G. The Mechanical Design Process. 4th ed. New York: McGraw-Hill, 2010. $448 \mathrm{p}$.

ULRICH; EPPINGER. Product Design and Development. 5th ed. McGraw-Hill Education, May, 2011. 432 p.

PHAM, J.; YANG, P.; CHOO, J.; HU, D. The Hydrodynamics of Urination: to drip or jet. In: 66th Annual Meeting of the APS division of fluid dynamics, v58, n.18, Brigham Young University, 24 november, 2013. Pennsylvania, USA. Disponível em: <http://meetings.aps.org/link/BAPS.2013.DFD.E9.4>

DRAGAN, V. A New Mathematical Model for Coandă Effect Velocity Approximation. Incas Bulletin, v4, Issue 4, p.85-92, 2012. Disponível em: <http://bulletin.incas.ro/files/dragan_v__v4_iss_4_full.pdf> 